\title{
Article
}

\section{The effect of proprioceptive knee bracing on knee stability during three different sport related movement tasks in healthy subjects and the implications to the management of Anterior Cruciate Ligament (ACL) injuries}

Hanzlíková, I, Richards, Jim, Tomsa, M, Chohan, Ambreen, May, Karen Alison, Smékal, D and Selfe, James

Available at http://clok.uclan.ac.uk/15004/

Hanzlíková, I, Richards, Jim ORCID: 0000-0002-4004-3115, Tomsa, M, Chohan, Ambreen ORCID: 0000-0003-0544-7832, May, Karen Alison ORCID: 00000001-9621-8466, Smékal, D and Selfe, James (2016) The effect of proprioceptive knee bracing on knee stability during three different sport related movement tasks in healthy subjects and the implications to the management of Anterior Cruciate Ligament (ACL) injuries. Gait and Posture, 48. pp. 165-170. ISSN 0966-6362

It is advisable to refer to the publisher's version if you intend to cite from the work. http://dx.doi.org/10.1016/j.gaitpost.2016.05.011

For more information about UCLan's research in this area go to

http://www.uclan.ac.uk/researchgroups/ and search for <name of research Group>.

For information about Research generally at UCLan please go to http://www.uclan.ac.uk/research/

All outputs in CLoK are protected by Intellectual Property Rights law, including Copyright law. Copyright, IPR and Moral Rights for the works on this site are retained by the individual authors and/or other copyright owners. Terms and conditions for use of this material are defined in the policies page. 


\title{
The effect of proprioceptive knee bracing on knee stability during three different sport related movement tasks in healthy subjects and the implications to the management of Anterior Cruciate Ligament (ACL) injuries
}

\author{
I Hanzlíková ${ }^{1,}$ J Richards², M Tomsa ${ }^{3}$, A Chohan², K May², D Smékal ${ }^{1}$, J Selfe ${ }^{2}$ \\ ${ }^{1}$ Faculty of Physical Culture, Palacký University, Olomouc, Czech Republic \\ ${ }^{2}$ Allied Health Research Unit, University of Central Lancashire, UK \\ ${ }^{3}$ Faculty of Health Science, Palacký University, Olomouc, Czech Republic
}

Keywords: Kinematics, Kinetics, Knee Instability, Bracing

Corresponding author:

Ivana Hanzlíková- mob.: +420720156862, email: xhanzlikova@gmail.com

\section{Highlights}

- The pivot turn jump showed the largest knee valgus and internal rotation angle

- No differences were seen in the sagittal plane between brace and no brace

- Bracing showed an improvement in coronal and transverse plane knee control

- The use of proprioceptive braces may help to decrease risk of knee injuries

\begin{abstract}
Introduction: Proprioceptive knee braces have been shown to improve knee mechanics, however much of the work to date has focused on tasks such as slow step down tasks rather than more dynamic sporting tasks.

Objective: This study aimed to explore if such improvements in stability may be seen during faster sports specific tasks as well as slower tasks.

Method: Twelve subjects performed a slow step down, single leg drop jump and pivot turn jump with and without a silicone web brace. 3D kinematics of the knee were collected using a ten camera Qualisys motion analysis system. Reflective markers were placed on the foot, shank, thigh and pelvis using the Calibrated Anatomical Systems Technique. A two way ANOVA with repeated measures was performed with post-hoc pairwise comparison to explore the differences between the two conditions and three tasks.
\end{abstract}

Results: Significant differences were seen in the knee joint angles and angular velocities in the sagittal, coronal and transverse planes between the tasks. The brace showed a reduction in knee valgum and internal rotation across all tasks, with the most notable effect during the single leg drop jump and pivot turn jump. The transverse plane also showed a significant reduction in the external rotation knee angular velocity when wearing the brace.

Discussion: The brace influenced the knee joint kinematics in coronal and transverse planes which confirms that such braces can have a significant effect on knee control during dynamic tasks. Further studies are required exploring the efficacy of proprioceptive braces in athletic patient cohort.

\section{Acknowledgements}

This study is partly founded by Erasmus+ program who have sponsored two masters students. The braces were supplied by DJO Global, Inc. The suppliers played no role in the design, execution, analysis and interpretation of the data or writing of this study. 


\section{Introduction}

Recent advances in knee brace design have led to the development of new designs of proprioceptive bracing. The Reaction Brace is distinct alternative to the basic knee sleeve, and is made from elastometric web. Developers of the brace claim that the shock-absorbing elastometric design dissipates peak stress and enhance patellar tracking. Khadavi et al [1] showed that the Reaction Brace reduces knee pain, increase function and enhance quality of life with individuals with patellofemoral pain. Selfe et al $[2,3]$ have previously shown on healthy participants and patients with patellofemoral pain that taping and soft and flexible braces can offer an improvement in movement control in the coronal and transverse planes. This may partially be explained by Edin [4] who stated that the stabilizing effects of taping techniques may be due to altered somatosensory inflow from the knee joint. Anterior Cruciate ligament (ACL) injuries are common in sports and often occur during non-contact cutting, jumping and pivoting activities [5, 6]. Kobayashi et al [7] observed that $55.2 \%$ of non-contact injury happened in women due to "dynamic valgus position of the knee". Landing has also been reported to cause a high anterior sheer force of the proximal tibia in combination with internal rotation of the knee and is reported as one of the most frequent mechanisms of ACL injury [8].

Each year in the United States there are approximately 250,000 ACL injuries, or 1 in 3,000 in the general population $[9,10]$. Numerous theories have been proposed to explain what predisposes patients to noncontact ACL injury. These theories are divided into four categories: hormonal, anatomic, environmental and neuromuscular [11]. Previous studies have shown that knee braces may improve functional performance during tasks such as single limb balance in individuals with ACL injuries [12, 13]. Butler et al. [14] also showed changes in landing mechanics in patients following ACL reconstruction while wearing a brace. To date no study has determined the size and nature of the effects of using proprioceptive knee bracing during more dynamic tasks on 3D knee mechanics.

The aim of knee bracing is to reduce pain and improve knee joint control through mechanical support of the joint. However, proprioception has also been identified as an important mechanism in managing knee instability and ACL injuries [15]. The skin contact from bracing could provide more afferent information to the brain due to cutaneous sensory stimulation and thereby improve neuromuscular control of the knee joint [16]. Any changes could be due to changes in neuromuscular control influenced by changed exteroception.

The first stage of this work is to determine if such bracing changes the knee stability in a group of healthy individuals during tasks used in clinical assessment and sporting activities, this data will also serve as a reference for further work on individuals with ACL injuries. This study aimed to determine any differences in knee movement and moments at the knee with and without a silicon web design brace.

\section{Method}

Twelve healthy participants, 7 men and 5 women, mean age 26.9( $\pm .6 .7)$, mean height $172.8 \mathrm{~cm}( \pm 14.5)$, mean weight $75.1 \mathrm{~kg}( \pm 12.5)$, mean BMI 25.2 ( \pm 3.1$)$ were recruited from a staff and student population at the University of Central Lancashire. 
All participants fulfilled the inclusion criteria of; no current musculoskeletal injuries or disorders, no history of surgery or traumatic injury to the lower extremities or lower back, no history of medical conditions that limit physical activity. All data collection conformed to the Declaration of Helsinki and volunteers gave written informed consent prior to participation.

Each subject performed 5 repetitions of: a slow step down, single leg drop jump and a pivot turn jump under two conditions (a) no brace (b) Reaction Brace, Figure 1. A number of practice attempts at each task were allowed until each participant indicted that they were ready. The order of the conditions was randomised and all testing for each participant was performed on one day. During the tasks participants wore their own sport footwear. For the step down task participants were asked to step down as slowly as possible from a $20 \mathrm{~cm}$ step landing with the heel of the contralateral limb. For the single leg drop jump participants were asked to begin by standing on one foot on top of the $20 \mathrm{~cm}$ step, then drop off the box landing on the same foot. For the pivot turn jump participants were asked to hop forwards approximately $60 \mathrm{~cm}$ and immediately pivot with internal rotation and hop back to the starting point in one movement. Kinetic data were collected at $200 \mathrm{~Hz}$ using two AMTI force platforms. Kinematic data were collected using a ten camera Oqus motion analysis system (Qualisys medical AB, Gothenburg, Sweden) at $100 \mathrm{~Hz}$. Reflective markers were placed on the foot, shank and thigh using the Calibrated Anatomical System Technique [17]. The thigh and shank marker clusters were placed above and below the brace respectively, Figure 1. Raw kinematic and kinetic data were exported to Visual3D (C-Motion Inc., USA). Kinematic and kinetic data were filtered using fourth order Butterworth filters with cut off frequencies of 15 and $25 \mathrm{~Hz}$, respectively. Joint kinematics were calculated relative to the shank coordinate system. The kinematics were calculated based on the cardan sequence of $\mathrm{XYZ}$, equivalent to the joint coordinate system proposed by Grood and Suntay [18]. Knee joint kinetics were calculated using standard inverse dynamic methods, relative to the shank coordinate system. The kinematic and kinetic data about the knee were then quantified from initial contact to the maximum knee flexion angle to allow the eccentrically controlling phase in single limb support to be explored. All data were found to be normally distributed and suitable for parametric testing. A two way ANOVA with repeated measures was performed with a Fisher's Least Significant Difference posthoc Pairwise comparison to explore the differences between the two conditions and three tasks for the biomechanical parameters.

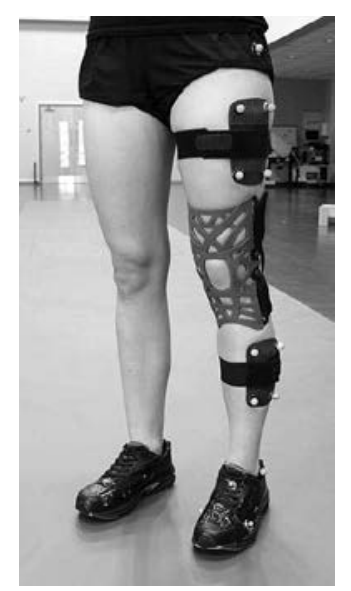

Figure 1: Reaction Brace 


\section{Results}

Although the tasks were demanding, no adverse incidents occurred. The mean values for the different tasks for the two conditions are presented in table 1. The Pairwise comparisons showed significant differences between the tasks in knee joint angles and knee angular velocities in the sagittal, coronal and transverse planes, table 2 . In the sagittal plane significant differences were seen in knee joint angles and angular velocity between slow step down and single leg drop jump, slow step down and pivot turn jump and in the angular velocity between single leg drop jump and pivot turn jump, table 2. Slow step down showed the greatest knee flexion angle, single leg drop jump showed the greatest knee flexion velocity and pivot turn jump showed the greatest knee extension and range of angular velocity, table 1 . In the coronal plane significant differences were seen in knee joint angles and angular velocity between slow step down and pivot turn jump, and in the angular velocity between slow step down and single leg drop jump, and in the valgus angle and range of motion between single leg drop jump and pivot turn jump, table 2. Pivot turn jump and single leg drop jump showed similar coronal plane angular velocities which were significantly greater than those during slow step down, table 1. In the transverse plane significant differences were seen between all tasks for all angles and angular velocities with the exception of peak internal and external angles between slow step down and single leg drop jump and peak internal rotation angular velocity between single leg drop jump and pivot turn jump, table 2. Pivot turn jump showed the greatest knee angles in transversal plane. The transverse plane angular velocities were similar for single leg drop jump and pivot turn jump and were significantly greater than slow step down, table 1.

The brace had no effect on the sagittal plane kinematics, however significant differences were seen in the coronal and transverse planes. The comparison between no brace and brace showed a significant difference in the knee varus and valgus knee angles, with the valgus angle showing a $2.4^{\circ}$ (30\%) reduction in the range of motion in the coronal plane $(\mathrm{p}=0.023)$ when wearing the brace. A significant interaction was seen between condition and task for knee valgus angle $(p=0.001)$. Further post hoc testing showed no significant difference between knee brace and no brace for step down; however bracing showed significantly less knee valgum during single leg drop jump( $\mathrm{p}=0.018)$ with a mean difference of 2.7 degrees, and for pivot turn jump with a mean difference of 3.8 degrees $(p=0.002)$. The knee varus angle showed a significant increase when wearing the brace $(p=0.035)$ with a mean difference of 1.5 degrees across all tasks. Further post hoc t-tests showed that the brace showed no significant difference for slow step down $(\mathrm{p}=0.108)$ or for pivot turn jump $(\mathrm{p}=0.359)$ but did show a significant difference during single leg drop jump with a mean difference of 2.1 degrees $(p=0.008)$. A significant interaction was seen between condition and task for range of motion in the coronal plane. Further post hoc tests showed no significant differences between no brace and brace for slow step down $(\mathrm{p}=0.065)$ and for single leg drop jump ( $\mathrm{p}=0.364)$. However a significant reduction in the varus/valgus range of motion was seen in the pivot turn jump, with a mean reduction of 3.0 degrees $(p=0.007)$, a $25 \%$ reduction of the varus/valgus range of motion when wearing the brace, table 3 .

The peak internal knee rotation was shown to be significantly reduced $(\mathrm{p}=0.035)$ when wearing the brace by $2.4^{\circ}, 21 \%$ total range of motion. A significant interaction was seen for internal knee rotation between condition and task for peak internal knee 
rotation. Further post hoc testing showed the effect due to the brace was not significant for slow step down $(\mathrm{p}=0.716)$ or for single leg drop jump $(\mathrm{p}=0.106)$, but was significantly reduced for pivot turn jump with a mean difference of 5.2 degrees $(p=0.002)$ when wearing the brace. The range of internal/external motion of the knee was also significantly reduced from $11.5^{\circ}$ to $9.3^{\circ}(p=0.003)$ when wearing the brace. A significant interaction was seen between condition and task for range of internal/external. Further post hoc testing showed no significant difference for slow step down $(\mathrm{p}=0.662)$ or for single leg drop jump ( $\mathrm{p}=0.682)$, however there was a significant reduction during the pivot turn jump from $19.6^{\circ}$ to $13.5^{\circ}(\mathrm{p}=0.005)$, a $31 \%$ reduction when wearing the brace, table 3.

No significant differences were seen between brace and no brace in the sagittal and coronal plane knee angular velocity in terms of minimum values, maximum values and ranges of angular velocities. However, the transverse plane showed a significant reduction between brace and no brace in the external rotation knee angular velocity $(\mathrm{p}=0.008)$, with the brace reducing the external rotation knee angular velocity from $122.7 \%$ s to $94.0 \%$ s. A significant interaction was seen between condition and task for external rotation knee angular velocity. Further post hoc testing showed no significant difference for slow step down with a mean difference of 4.3, or single leg drop jump with a mean difference of 8.9, however there was significance difference between brace and no brace for pivot turn jump with a mean reduction of 72.9 degrees/s $(\mathrm{p}<0.001)$ during the pivot turn jump when wearing the brace. No significant differences in the range of internal/external rotational knee angular velocity were seen between no brace and brace, however a significant interaction $(\mathrm{p}=0.007)$ was seen between condition and task. Further post hoc testing showed significant differences between no brace and brace for slow step down with a mean difference of 8.6 degree/s $(\mathrm{p}=0.036)$, a $25 \%$ reduction, and for pivot turn jump with a mean difference of 106.8 degrees/s $(p=0.022)$, a $24 \%$ reduction when wearing the brace. However, no significant differences were seen between brace and no brace for single leg drop jump. In addition, significant differences were also seen in the landing positions of the knee during the pivot turn jump task in the transverse plane $(\mathrm{p}=0.002)$, table 3. During landing without the brace, the knee showed an internal rotation of $7.6^{\circ}$, whereas with the brace the knee was near to a neutral position $0.4^{\circ}$, table 1 . No significant differences were seen between brace and no brace in the sagittal plane knee angle landing position during pivot turn jump or for the single leg drop jump.

\section{Discussion}

This study examined 3D kinematics of the knee during three different tasks. The slow step down is a controlled movement which involves the knee joint starting from a relatively stable extended position and then slowly flexing towards a more unstable position, which requires increasing eccentric muscular control [2]. During the first $30^{\circ}$ of flexion the ACL is at the greatest tension during flexion which prevents anterior translation of the proximal tibia [19]. In extreme cases, the eccentric pull of the extensor muscles may cause damage to the ACL. Contraction of the quadriceps femoris creates two forces, one pulls the patella towards femur increasing patellofemoral joint compression and the second causes an anterior shearing movement of proximal tibia relative to the femur. This second shearing force can cause damage of ACL, especially in hypermobile individuals. The forces increasing with increasing angle of flexion, nevertheless most of injuries happen during the first 
30 degrees of flexion because during these angles the hamstrings, which cause posterior translation of proximal tibia are relatively inactive [20,21]. Compared to the other tasks studied the slow step down requires the largest range of motion in the sagittal plane. The range of motion in coronal and transversal planes were comparable to that of the single leg drop jump although the angular velocities were significantly smaller than in the single leg drop jump and pivot turn jump in all planes. Patients with ACL deficits often feel pain and instability during stair decent, and in more extreme situations some patients cannot control the movement into knee flexion, and the knee gives way. The aim of the slow step down used in this study was to determine if proprioceptive knee bracing could influence slow eccentric control. However seventy percent of all ACL injuries happen during sports such as soccer and women's gymnastics [19, 22], with most injuries occurring in non-contact. Injuries are often associated with a sudden deceleration, change of direction or landing [7]. All of which are represented in the single leg drop jump and pivot turn jump tasks which aim to replicate the movements which are risk factors for ACL injury.

The pivot turn jump showed the largest knee valgus and internal rotation angle, both could contribute to a greater load on the ACL and therefore produce the highest injury risk of the tasks tested. No significant differences were seen in the sagittal plane between brace and no brace in any of the tasks, this is in agreement with Selfe et al [2]. In the coronal plane the brace showed a significant difference in the knee position with a move from valgus towards a more neutral position. The brace had the largest effect during pivot turn jump reducing knee valgus and internal rotation. This implies there is a change in movement strategy when wearing the brace applied away from valgus internal rotation or "dynamic valgus position of the knee" which has been shown to be an important risk factor for ACL injury [7, 23]. No significant reduction of range of motion in the coronal plane was seen during the slow step down task however a similar study (Selfe et al., 2008) [2] found a reduction in the range of motion for this task, however the brace did reduce internal rotation of the knee in the transverse plane which is in agreement with Selfe et al. (2011) [3].

The stability of the joint through the coordination of the neuromuscular system can be defined as the ability to maintain or control joint movement or position [19]. If the range of motion in the transverse and coronal planes decreases this could suggest better control of the knee [2, 24], however, this does not necessarily tell us about the control of these movements. For this reason knee angular velocities were also assessed in all planes. This could give a better measure of dynamic control and stability of the knee joint, which has also been related to the force generation and dynamics of muscle activation [25]. There are currently no studies assessing angular velocities in all three planes, although there are a few studies which assess angular velocity in the sagittal plane [2, 26, 27]. Selfe et al [2] measured knee angular velocity in the sagittal plane during step descent for patients with patellofemoral pain under different treatment modalities. They did not find any significant differences of mean, maximum and minimum which is in agreement with this study. The speed of movement towards knee valgus has also been identified as an injury risk for the medial collateral ligament and ACL [28]. The findings in this study suggests that the brace improves the control of the peak valgus and external rotation velocities which may help in the prevention of ACL injury or help people with ACL deficiency [28]. 
The exact mechanisms through which the brace improved control during the tasks cannot be determined from this study, however it has previously been demonstrated that bracing and taping can alter brain responses during proprioception tasks [2, 24, 29]. Further work is needed exploring if different movement strategies exist with changing external conditions or internal conditions such as pain and skin sensation. There was some variation in movement strategy for the different tasks, however this study showed that the use of bracing can influence strategy of movement, possibly by the additional afferent information produced by the knee brace. This was particularly noteworthy in the pivot turn jump which showed that when participants were wearing the brace they landed in a more neutral knee position. This suggests that using the brace in sport where this type of one leg turning movement frequently occurs may help to decrease risk of knee soft tissues injuries.

\section{Conclusion}

The silicone web brace changed the knee joint kinematics in coronal and transverse plane which supports the notion that bracing can have a significant effect on joint control. However, to confirm this, further studies are required exploring the effectiveness of such soft proprioceptive braces on patient cohorts, in particular on individuals who suffer knee pain and those who wish to return to sport following anterior cruciate ligament injury.

\section{Conflict of interest statement}

We can confirm that there is no conflict of interests for any of the authors.

\section{References}

[1] Khadavi MJ, Chen YT, Fredericson M. A Novel Knee Orthosis in the Treatment of Patellofemoral Pain Syndrome. Open J. Ther. Rehabil 2015;3:56-61.

[2] Selfe J, Richards J, Thewlis D, Kilmurray S. The biomechanics of step descent under different treatment modalities used in patellofemoral pain. Gait Posture 2008;27:258-263.

[3] Selfe J, Thewlis D, Hill S, Whitaker J, Sutton C, Richards J. A clinical study of the biomechanics of step descent using different treatment modalities for patellofemoral pain. Gait Posture 2011;34:92-96.

[4]Edin B. Cutaneous afferents provide information about knee joint movements in humans. J Physiol2001;531:289-297.

[5] Clayton RA, Court-Brown CM. The epidemiology of musculoskeletal tendinous and ligamentous injuries. Injury 2008;39:1338-1344.

[6] Majewski M, Susanne H, Klaus S. Epidemiology of athletic knee injuries: A 10year study. Knee 2006;13:184-188.

[7] Kobayashi H, Kanamura T, Koshida S, Miyashita K, Okado T, Shimizu T, Yokoe $\mathrm{K}$. Mechanisms of the anterior cruciate ligament injury in sports activities: A twentyyear clinical research of 1,700 athletes. J Sports Sci Med 2010;9:669-675.

[8] Meyer EG, Haut RC. Anterior cruciate ligament injury induced by internal tibial torsion or tibiofemoral compression. J Biomech2008;41:3377-3383.

[9] Toth AP, Cordasco FA. Anterior cruciate ligament injuries in the female athlete. J GendSpecif Med 2001;4:25-34.

[10] Hewett TE, Lindenfeld TN, Riccobene JV, Noyes FR. The effect of neuromuscular training on the incidence of knee injury in female athletes. A prospective study. Am J Sports Med 1999;27:699-706.

[11] Boden BP, Griffin LY, Garrett WE. Etiology and prevention of noncontact 
ACL injury. Phys Sports Med 2000;29:53-60.

[12] Birmingham TB, Kramer JF, Kirkley A, Inglis JT, Spaulding SJ, Vandervoort

AA. Knee bracing after ACL reconstruction: effects on postural control and proprioception. Med Sci Sports Exerc2001;33:1253-1258.

[13] Wu GK, Ng GY, Mak AF. Effects of knee bracing on the sensorimotor function of subjects with anterior cruciate ligament reconstruction. Am J Sports Med 2001;29:641-645.

[14] Butler RJ, Dai B, Garrett WE, Queen RM. Changes in landing mechanics in patients following anterior cruciate ligament reconstruction when wearing an extension constraint knee brace. Sports Health 2014;6:203-209.

[15] Théoret D, Lamontagne $M$. Study on three-dimensional kinematics and electromyography of ACL deficient knee participants wearing a functional knee brace during running. Knee Surg Sports TraumatolArthrosc2006;14:555-563.

[16] Thijs Y, Vingerhoets G, Pattyn E, Rombaut L, Wityrouw E. Does bracing influence brain activity during knee movement: an fMRI study. Knee Surg Sports TraumatolArthrosc2010;18:1145-1149.

[17] Cappozzo A, Catani F, Leardini A, Benedeti MG, Della CU. Position and orientation in space of bones during movement: Anatomical frame definition and determination. Clinical Biomechanics 1995;10:171-178.

[18] Grood ES, Suntay WJ. A joint coordinate system for the clinical description of three-dimensional motions: application to the knee. J BiomechEng1983;105:136- 144.

[19] ProdromosCh, Brown Ch, Fu FH, Georgoulis AD, Gobbi A, Howell SM, Johnson D, Paulos LE, Shelbourne KD. The anterior cruciate ligament: Reconstruction and basic science. 1th ed. Philadelphia: Elsevier Saunders;2008.

[20] Shimokochi Y, Shultz SJ. Mechanisms of noncontact anterior cruciate ligament injury. J Athl Train 2008;43:396-408.

[21] Kapandji IA. The physiology of the joints. Lower limb. 2nd ed.Edinburgh: Churchill Livingstone; 1987.

[22] Hootman JM, Dick R, Agel J. Epidemiology of collegiate injuries for 15 sports: summary and recommendations for injury prevention initiatives. $J$ Athl Train 2007;42:311-319.

[23] Dai B, Herman D, Liu H, Garrett WE, Yu B. Prevention of ACL injury, part I: injury characteristics, risk factors, and loading mechanism. Res Sports Med 2012;20:180-197.

[24] Richards J, Chohan A, Janssen J, Selfe J. Taping and bracing of the knee joint: A ladder of conservative intervention for patellofemoral pain. Physiotherapy 2015;101:1280-1281.

[25] Granata KP, Abel MF, Damiano DL. Joint angular velocity in spastic gait and the influence of muscle-tendon lengthening. J Bone Joint Surg Am 2000;82:174-86.

[26] Hahn D, Herzog W, Schwirtz A. Interdependence of torque, joint angle, angular velocity and muscle action during human multi-joint leg extension. Eur J ApplPhysiol2014;114:1691-1702.

[27] Wang LI. The lower extremity biomechanics of single-and double-leg stop-jump tasks. J Sports Sci Med 2011;10:151-156.

[28] Meyer EG, Haut RC. Excessive compression of the human tibiofemoral joint causes ACL rupture. J Biomech2005;38:2311-2316.

[29] Callaghan MJ, Selfe J, Bagley PJ, Oldham JA. The effects of patellar taping on knee joint proprioception. J Athl Train 2002;37:19-24. 


\begin{tabular}{|c|c|c|c|c|c|c|c|}
\hline & \multirow[b]{2}{*}{ Conditions } & \multicolumn{3}{|c|}{$\begin{array}{c}\text { Angle } \\
\text { Mean (sd) }\end{array}$} & \multicolumn{3}{|c|}{$\begin{array}{c}\text { Angular Velocity } \\
\text { Mean (sd) } \\
\end{array}$} \\
\hline & & $\begin{array}{l}\text { Step } \\
\text { Down }\end{array}$ & $\begin{array}{l}\text { Drop } \\
\text { Jump }\end{array}$ & $\begin{array}{l}\text { Pivot turn } \\
\text { jump }\end{array}$ & $\begin{array}{l}\text { Step } \\
\text { Down }\end{array}$ & $\begin{array}{l}\text { Drop } \\
\text { Jump }\end{array}$ & $\begin{array}{l}\text { Pivot turn } \\
\text { jump }\end{array}$ \\
\hline \multicolumn{8}{|l|}{ Sagittal plane } \\
\hline \multirow{2}{*}{ Extension(-) } & No Brace & $\begin{array}{l}12.7 \\
(7.2)\end{array}$ & $\begin{array}{l}12.7 \\
(5.5)\end{array}$ & $\begin{array}{l}11.1 \\
(7.2)\end{array}$ & $\begin{array}{l}7.5 \\
(6.2) \\
\end{array}$ & $\begin{array}{l}-2.0 \\
(33.3)\end{array}$ & $\begin{array}{l}-318.3 \\
(104.5)\end{array}$ \\
\hline & Brace & $\begin{array}{l}14.2 \\
(7.7)\end{array}$ & $\begin{array}{l}13.1 \\
(5.6)\end{array}$ & $\begin{array}{l}11.4 \\
(4.0)\end{array}$ & $\begin{array}{l}10.0 \\
(10.4)\end{array}$ & $\begin{array}{l}19.1 \\
(51.4)\end{array}$ & $\begin{array}{c}-326.1 \\
(127.9)\end{array}$ \\
\hline \multirow{2}{*}{ Flexion $(+)$} & No Brace & $\begin{array}{l}77.3 \\
(5.0)\end{array}$ & $\begin{array}{l}52.6 \\
(8.4)\end{array}$ & $\begin{array}{l}53.7 \\
(7.9)\end{array}$ & $\begin{array}{l}63.2 \\
(31.9)\end{array}$ & $\begin{array}{l}443.4 \\
(105.0)\end{array}$ & $\begin{array}{l}384.2 \\
(118.3)\end{array}$ \\
\hline & Brace & $\begin{array}{l}79.7 \\
(6.6)\end{array}$ & $\begin{array}{l}51.5 \\
(7.4)\end{array}$ & $\begin{array}{l}54.2 \\
(7.3)\end{array}$ & $\begin{array}{l}53.5 \\
(17.2)\end{array}$ & $\begin{array}{l}468.5 \\
(111.5)\end{array}$ & $\begin{array}{l}363.2 \\
(55.9)\end{array}$ \\
\hline \multirow{2}{*}{ Range of motion } & No Brace & $\begin{array}{l}64.6 \\
(5.5)\end{array}$ & $\begin{array}{l}40.0 \\
(8.2)\end{array}$ & $\begin{array}{l}42.6 \\
(10.6) \\
\end{array}$ & $\begin{array}{l}55.8 \\
(33.3) \\
\end{array}$ & $\begin{array}{l}445.3 \\
(114.4)\end{array}$ & $\begin{array}{l}702.5 \\
(161.1)\end{array}$ \\
\hline & Brace & $\begin{array}{l}65.6 \\
(6.1)\end{array}$ & $\begin{array}{l}38.4 \\
(6.3)\end{array}$ & $\begin{array}{l}42.9 \\
(8.0)\end{array}$ & $\begin{array}{l}43.6 \\
(18.1)\end{array}$ & $\begin{array}{l}449.4 \\
(144.7)\end{array}$ & $\begin{array}{l}689.3 \\
(129.5)\end{array}$ \\
\hline \multirow[t]{2}{*}{ Landing position } & No Brace & - & $\begin{array}{l}12.5 \\
(5.4)\end{array}$ & $\begin{array}{l}14.9 \\
(5.2)\end{array}$ & - & - & - \\
\hline & Brace & - & $\begin{array}{l}13.1 \\
(5.4)\end{array}$ & $\begin{array}{l}16.7 \\
(4.7)\end{array}$ & - & - & - \\
\hline \multicolumn{8}{|l|}{ Coronal plane } \\
\hline \multirow{2}{*}{ Valgus Angle (-) } & No Brace & $\begin{array}{l}-3.8 \\
(4.7) \\
\end{array}$ & $\begin{array}{l}-5.4 \\
(6.2) \\
\end{array}$ & $\begin{array}{l}-10.2 \\
(6.4)\end{array}$ & $\begin{array}{r}-8.8 \\
(4.8) \\
\end{array}$ & $\begin{array}{c}-100.7 \\
(62.3)\end{array}$ & $\begin{array}{l}-103.2 \\
(26.7)\end{array}$ \\
\hline & Brace & $\begin{array}{r}-3.2 \\
(5.9)\end{array}$ & $\begin{array}{l}-2.7 \\
(7.0)\end{array}$ & $\begin{array}{l}-6.3 \\
(8.2)\end{array}$ & $\begin{array}{r}-9.9 \\
(9.9)\end{array}$ & $\begin{array}{r}-101.7 \\
(108.6)\end{array}$ & $\begin{array}{c}-86.2 \\
(51.6)\end{array}$ \\
\hline \multirow{2}{*}{ Varus Angle (+) } & No Brace & $\begin{array}{l}1.6 \\
(7.3) \\
\end{array}$ & $\begin{array}{l}0.6 \\
(5.2)\end{array}$ & $\begin{array}{l}2.0 \\
(8.0) \\
\end{array}$ & $\begin{array}{l}10.2 \\
(5.7)\end{array}$ & $\begin{array}{l}73.3 \\
(58.7)\end{array}$ & $\begin{array}{l}105.5 \\
(56.1) \\
\end{array}$ \\
\hline & Brace & $\begin{array}{l}3.3 \\
(8.1)\end{array}$ & $\begin{array}{l}2.8 \\
(5.7)\end{array}$ & $\begin{array}{l}2.7 \\
(7.9)\end{array}$ & $\begin{array}{l}11.1 \\
(7.5)\end{array}$ & $\begin{array}{l}90.4 \\
(55.1)\end{array}$ & $\begin{array}{l}88.6 \\
(49.7)\end{array}$ \\
\hline \multirow{2}{*}{ Range of motion } & No Brace & $\begin{array}{l}5.4 \\
(4.6)\end{array}$ & $\begin{array}{l}6.0 \\
(1.8)\end{array}$ & $\begin{array}{l}12.1 \\
(3.9)\end{array}$ & $\begin{array}{l}19.0 \\
(5.0)\end{array}$ & $\begin{array}{l}174.0 \\
(88.0) \\
\end{array}$ & $\begin{array}{l}208.7 \\
(73.9)\end{array}$ \\
\hline & Brace & $\begin{array}{l}6.4 \\
(4.5)\end{array}$ & $\begin{array}{l}5.5 \\
(2.4)\end{array}$ & $\begin{array}{l}9.1 \\
(4.0)\end{array}$ & $\begin{array}{l}21.0 \\
(13.1) \\
\end{array}$ & $\begin{array}{l}192.1 \\
(134.8)\end{array}$ & $\begin{array}{l}174.8 \\
(78.8) \\
\end{array}$ \\
\hline \multicolumn{8}{|l|}{ Transverse plane } \\
\hline \multirow{2}{*}{ External rotation (-) } & No Brace & $\begin{array}{l}-2.1 \\
(6.4)\end{array}$ & $\begin{array}{l}-2.9 \\
(7.2)\end{array}$ & $\begin{array}{r}-8.1 \\
(7.5) \\
\end{array}$ & $\begin{array}{l}-17.3 \\
(7.7) \\
\end{array}$ & $\begin{array}{l}-130.8 \\
(88.2)\end{array}$ & $\begin{array}{l}-220.1 \\
(58.6)\end{array}$ \\
\hline & Brace & $\begin{array}{r}-2.1 \\
(6.1) \\
\end{array}$ & $\begin{array}{r}-4.4 \\
(5.0) \\
\end{array}$ & $\begin{array}{r}-7.3 \\
(6.3) \\
\end{array}$ & $\begin{array}{l}-13.0 \\
(5.9) \\
\end{array}$ & $\begin{array}{r}-121.9 \\
(105.0)\end{array}$ & $\begin{array}{l}-147.3 \\
(65.2)\end{array}$ \\
\hline \multirow{2}{*}{ Internal rotation $(+)$} & No Brace & $\begin{array}{l}4.5 \\
(6.5)\end{array}$ & $\begin{array}{l}5.5 \\
(7.5)\end{array}$ & $\begin{array}{l}11.5 \\
(7.0)\end{array}$ & $\begin{array}{l}17.1 \\
(10.4)\end{array}$ & $\begin{array}{l}172.8 \\
(44.9) \\
\end{array}$ & $\begin{array}{l}228.2 \\
(65.4)\end{array}$ \\
\hline & Brace & $\begin{array}{l}4.1 \\
(5.4)\end{array}$ & $\begin{array}{l}3.7 \\
(7.0)\end{array}$ & $\begin{array}{l}6.2 \\
(7.3)\end{array}$ & $\begin{array}{l}12.8 \\
(7.5) \\
\end{array}$ & $\begin{array}{l}206.1 \\
(135.6)\end{array}$ & $\begin{array}{l}194.3 \\
(99.1) \\
\end{array}$ \\
\hline \multirow{2}{*}{ Range of motion } & No Brace & $\begin{array}{l}6.5 \\
(2.5)\end{array}$ & $\begin{array}{l}8.4 \\
(3.0)\end{array}$ & $\begin{array}{l}19.6 \\
(5.2) \\
\end{array}$ & $\begin{array}{l}34.3 \\
(13.8) \\
\end{array}$ & $\begin{array}{l}303.5 \\
(109.3)\end{array}$ & $\begin{array}{l}448.3 \\
(61.6)\end{array}$ \\
\hline & Brace & $\begin{array}{l}6.1 \\
(3.4)\end{array}$ & $\begin{array}{l}8.2 \\
(3.3)\end{array}$ & $\begin{array}{l}13.5 \\
(4.0)\end{array}$ & $\begin{array}{l}25.7 \\
(10.9)\end{array}$ & $\begin{array}{l}327.9 \\
(227.7)\end{array}$ & $\begin{array}{l}341.5 \\
(156.8)\end{array}$ \\
\hline \multirow[t]{2}{*}{ Landing position } & No Brace & - & - & $\begin{array}{l}7.6 \\
(9.8)\end{array}$ & - & - & - \\
\hline & Brace & - & - & $\begin{array}{l}0.4 \\
(7.5)\end{array}$ & - & - & - \\
\hline
\end{tabular}

Table 1. Means (SDs) for knee joint angles and angular velocities 


\begin{tabular}{|c|c|c|c|c|c|c|}
\hline & \multicolumn{2}{|c|}{$\begin{array}{l}\text { Step Down-Single leg } \\
\text { drop jump }\end{array}$} & \multicolumn{2}{|c|}{$\begin{array}{l}\text { Step Down- Pivot turn } \\
\text { jump }\end{array}$} & \multicolumn{2}{|c|}{$\begin{array}{c}\text { Single leg drop jump - } \\
\text { Pivot turn jump }\end{array}$} \\
\hline & $\begin{array}{c}\text { Mean } \\
\text { Difference }\end{array}$ & p-value & $\begin{array}{l}\text { Mean } \\
\text { difference }\end{array}$ & p-value & $\begin{array}{c}\text { Mean } \\
\text { difference }\end{array}$ & p-value \\
\hline \multicolumn{7}{|l|}{ Sagittal plane } \\
\hline Maximum flexion angle & 26.4 & $\mathrm{p}<0.001$ & 24.6 & $\mathrm{p}<0.001$ & -1.9 & 0.496 \\
\hline Range of motion & 25.9 & $\mathrm{p}<0.001$ & 22.4 & $\mathrm{p}<0.001$ & -3.53 & 0.296 \\
\hline Peak extension angular velocity (+) & 0.2 & 0.989 & 330.9 & $\mathrm{p}<0.001$ & 330.7 & $\mathrm{p}<0.001$ \\
\hline Peak flexion angular velocity (-) & -397.5 & $\mathrm{p}<0.001$ & -315.3 & $\mathrm{p}<0.001$ & 82.2 & 0.002 \\
\hline Range of angular velocity & 397.7 & $\mathrm{p}<0.001$ & 646.2 & $\mathrm{p}<0.001$ & 248.5 & $\mathrm{p}<0.001$ \\
\hline
\end{tabular}

\section{Coronal plane}

\begin{tabular}{lcccccc}
\hline Valgus angle & 0.6 & 0.513 & 4.8 & $\mathrm{p}<0.001$ & 4.2 & $\mathrm{p}<0.001$ \\
\hline Range of motion & 0.2 & 0.901 & -4.7 & $\mathrm{p}<0.001$ & -4.8 & 0.001 \\
\hline Peak valgus angular velocity (+) & 91.8 & 0.002 & 85.3 & $\mathrm{p}<0.001$ & -6.5 & 0.774 \\
\hline Peak varus angular velocity (-) & -71.2 & $\mathrm{p}<0.001$ & -86.4 & $\mathrm{p}<0.001$ & -15.2 & 0.197 \\
\hline Range of angular velocity & 163.1 & $\mathrm{p}<0.001$ & 171.7 & $\mathrm{p}<0.001$ & 8.7 & 0.775 \\
\hline
\end{tabular}

\section{Transverse plane}

\begin{tabular}{lcccccc}
\hline Maximum external rotation angle & 1.6 & 0.218 & 5.643 & $\mathrm{p}<0.001$ & 4.0 & 0.002 \\
\hline Maximum internal rotation angle & -0.4 & 0.771 & -4.585 & 0.003 & -4.2 & 0.005 \\
\hline Range of motion & 2.0 & 0.046 & 10.227 & $\mathrm{p}<0.001$ & 8.3 & $\mathrm{p}<0.001$ \\
\hline $\begin{array}{l}\text { Peak external rotation angular } \\
\text { velocity (+) }\end{array}$ & 111.2 & 0.001 & 168.574 & $\mathrm{p}<0.001$ & 57.4 & 0.012 \\
\hline $\begin{array}{l}\text { Peak internal rotation angular } \\
\text { velocity (-) }\end{array}$ & -174.5 & $\mathrm{p}<0.001$ & -196.294 & $\mathrm{p}<0.001$ & -21.8 & 0.279 \\
\hline Range of angular velocity & 285.7 & $\mathrm{p}<0.001$ & -364.868 & $\mathrm{p}<0.001$ & 79.2 & 0.016 \\
\hline
\end{tabular}

Table 2. Pairwise comparison of joint kinematics of the knee

\begin{tabular}{lccc}
\hline & Mean difference & Standard error & p-value \\
\hline Coronal plane & & & \\
\hline Valgus angle & -2.4 & 0.9 & 0.023 \\
\hline Varus angle & -1.5 & 0.6 & 0.035 \\
\hline Transverse plane & & 1.0 & 0.035 \\
\hline Maximum angle & 2.5 & 0.6 & 0.003 \\
\hline Range of motion & 2.2 & 8.9 & 0.008 \\
\hline $\begin{array}{l}\text { External rotation angular } \\
\text { velocity (-) }\end{array}$ & -28.7 & 1.8 & 0.002 \\
\hline $\begin{array}{l}\text { Landing position - pivot turn } \\
\text { jump }\end{array}$ & 7.2 & &
\end{tabular}

Table 3. Pairwise comparison between no brace and brace 